\title{
II-VI Quantum Dots as Fluorescent Probes for Studying Trypanosomatides
}

\author{
Adriana Fontes ${ }^{1}$, Beate. S. Santos ${ }^{2}$, \\ Claudilene R. Chaves ${ }^{2}$ and Regina C. B. Q. Figueiredo ${ }^{3}$ \\ ${ }^{1}$ Departamento de Biofísica e Radiobiologia, \\ Universidade Federal de Pernambuco, Recife \\ ${ }^{2}$ Departamento de Ciências Farmacêuticas, \\ Universidade Federal de Pernambuco, Recife \\ ${ }^{3}$ Centro de Pesquisa Aggeu Magalhães, \\ Fundação Oswaldo Cruz, Recife \\ Brazil
}

\section{Introduction}

Fluorescence provides a unique method for understanding how biomolecules interact with each other in many levels, from single cell to whole organisms. Researchers commonly use fluorescence-based techniques mainly due to its high specificity and sensitivity (capable of detecting even a single molecule) (Michalet et al., 2006; Giepmans et al., 2006). The evolution of tools based on fluorescence including new techniques (like multiphoton microscopy), new lasers and new fluorescent probes (presenting new features when compared to the traditional organic fluorophores), allowing us to take advantages of the full potential of fluorescence. This is the case of Quantum dots (QDs) that since the end the 90's have been increasingly used in biological and biomedical field.

Quantum dots are semiconductor nanoparticles, with typical dimensions ranging from 2 to $10 \mathrm{~nm}$. QDs are often referred as artificial atoms not only because electrons are dimensionally confined in these nanoparticles (just like in a real atom), but also because the QDs also present discrete energy levels and can give rise to fluorescence when excited by light. In general, QDs have been successfully used as fluorescent labels for imaging fixed and live cells and also small animals, immunoassays (Tian et al., 2010), diagnostic methodologies (Yezhelyev et al., 2006) and recently also for photodynamic therapy (Samia et al., 2006).

For an optimal performance in biological application, QDs have been synthesized in order to optimize their fluorescence, active surface and chemical stability. These necessary characteristics result in a nanostructured complex multilayered chemical assembly where: 1 . The chemical nature of the core is the main responsible for the fluorescence emission color. 2 . The passivation shell determines its brightness and photostability and 3 . The organic capping determines its stability and biological functionality, as shown in Figure 1. The passivation shell is defined as a chemical coating at the surface of the nanoparticle. This coating, composed of a 
few monolayers of another semiconductor material, helps to decrease the surface defects characteristic of a high surface/volume ratio of these nanometric systems. When this passivation shell is applied nanoparticles are called "core-shell" systems.

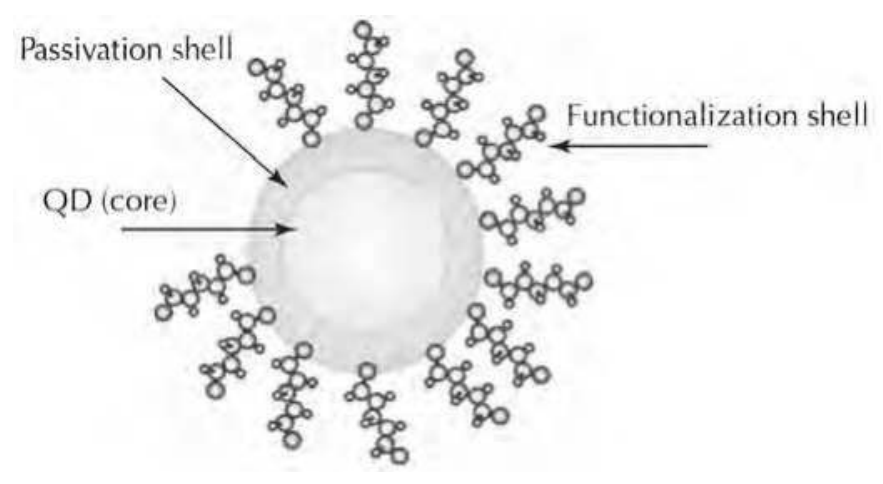

Fig. 1. Schematic representation of a semiconductor QD for biomedical application purposes (Santos et al., 2008).

Both core and shell usually are made of elements from II B and IV A group giving rise to core/shell nanoparticles such as CdTe/CdS, CdSe/ZnSe and ZnSe/ZnS. For active optical properties, the band gap of the semiconductor present in the shell is usually higher than the band gap of the core. QDs can be synthesized in organic or aqueous medium. When compared to organometallic routes, water-based QDs synthesis is cheaper, less toxic and intrinsically biocompatible for applications in biological fields (Santos et al., 2008). The stability of water dispersed QDs is generally accomplished by using charged organic molecules or polymers. A commonly used class of organic molecules is alkyl-thiol molecules (such as mercaptopropionic acid - MPA, mercaptoacetic acid - MAA and mercaptosuccinic acid - MSA) and more recently cysteine. These stabilizing agents have carboxyl or amine terminals that can be conjugated to biomolecules (such as proteins and antibodies) rendering more specificity for biological applications.

Despite the success of QDs as fluorescent probes, some drawbacks still exist (mainly when the application is focused in live cells and small animals). Synthesis of high quality water dispersed QDs, high stability in aqueous media at physiological $\mathrm{pH}$, full biocompatibility; narrow size distribution and (only) specific interactions with target molecules. Taken together these features are still hard tasks to be achieved. Moreover, little is still known about the mechanisms of QDs interactions with live biological systems and how these mechanisms can affect cellular functions. As in other classes of nanoparticles, the cellular uptake of QDs, for example, depends on the surface coating, the cell type and QDs size (Kelf et al., 2010). The comprehension of the interconnections existing between the cellular dynamics and the QDs kinetics (including the mechanisms of uptake and intracellular delivery), is an important step to engineering more functional QDs for biomedical research and also to take advantage of the QDs - cells interactions to understand basic cellular biology. 
In this context, the purpose of this Chapter is to discuss important characteristics that have to be considered when using QDs for live cells applications and to highlight the use of water dispersed $\mathrm{CdS} / \mathrm{Cd}(\mathrm{OH})_{2}$ and $\mathrm{CdTe} / \mathrm{CdS}$ QDs as a bioimaging tool to improve the comprehension of cell biology aspects of protozoa. Here we will focus on the Leishmania sp. and Trypanosoma cruzi protozoa which are the etiological agents of Leishmaniasis and Chagas disease respectively.

\section{QDs for life sciences applications}

QDs are colloidal semiconductor nanocrystals which have unique optical properties due to their 3D dimensional quantum confinement regime. These properties give to QDs some advantages over the conventional fluorescent dyes. Compared to organic fluorophores, the major advantages of interest to biologists offered by QDs are:

1. A broad absorption band, allowing a flexible cross section for multiphoton microscopy - as shown in Figure 2;

2. A size tunable emission wavelength which means that QDs of the same material, but with different sizes, can emit light of different colors (quantitatively speaking, the energy gap determines the wavelength of the fluorescence). Larger QDs emit fluorescence towards the red region as shown in Figure 3;

3. An active surface for chemical conjugation. QDs conjugated to proteins or antibodies play important roles, because they are inorganic-biological hybrids nanoparticles that combine characteristics of both materials, that is, the fluorescence properties of QDs with the biochemical functions of the proteins and antibodies.

4. High resistance to photobleaching: the most important advantage of QDs over organic dyes.
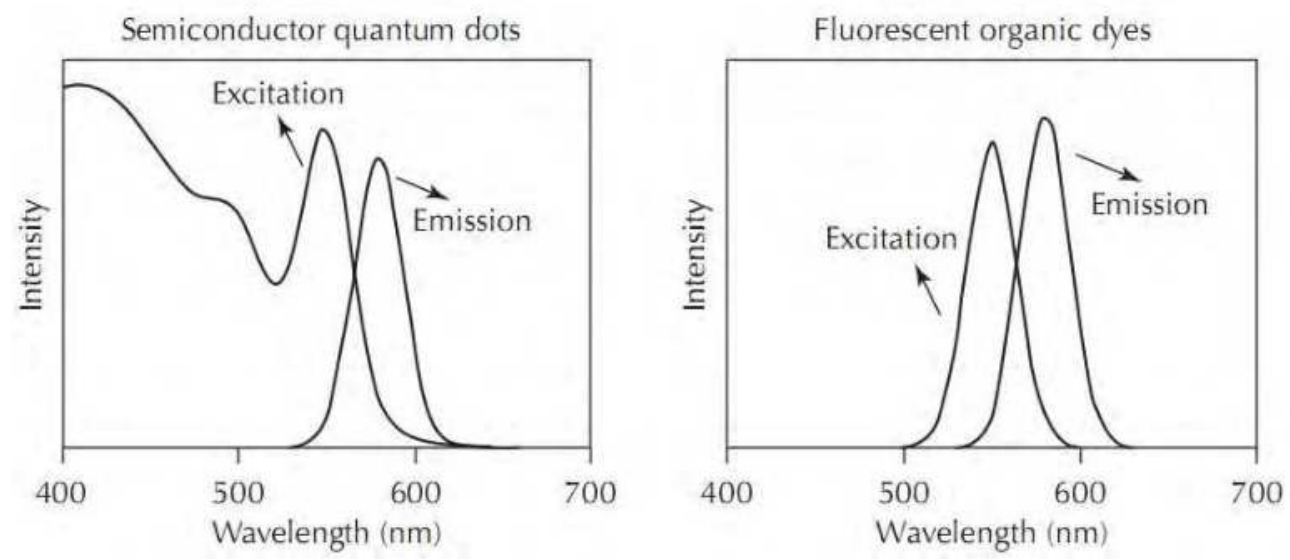

Fig. 2. A general comparative excitation and emission spectrum profile of QDs versus organic dyes (Santos et al., 2008). 
The feasibility of using QDs for antigen detection in fixed cells and tissues has been demonstrated in several studies. Specific genomic sequences and antigens could be labeled in fixed samples with great success by using QDs (Say et al., 2011; Barroso, 2011). On the other hand, the use of QDs for live cells imposes some challenges when compared to fixed samples and special care must be taken to guarantee that cell remain alive and healthy along all the experiment. Water dispersed QDs usually are less fluorescent than organic synthesized QDs. Conversely, due to their hydrophilic characteristic they are intrinsically more biocompatible than organic QDs. Before applying QDs as fluorescent probes for live cells it is necessary to analyze:

- QDs physico-chemical aspects (such as original emission/absorption and photophysical/chemical stability in biological media);

- QDs-cells interactions (for example: Do these cells have an active uptake? The size, surface electrical charges and the coating of QDs are important to QDs-cell interactions?);

- Intracellular labeling and non-specific interactions (which and where is the target biomolecule, inside the cell or on the cell membrane?);

- QDs toxicity (how and which QDs properties can affect cells? The influence of $\mathrm{pH}$, osmolarity and composition).

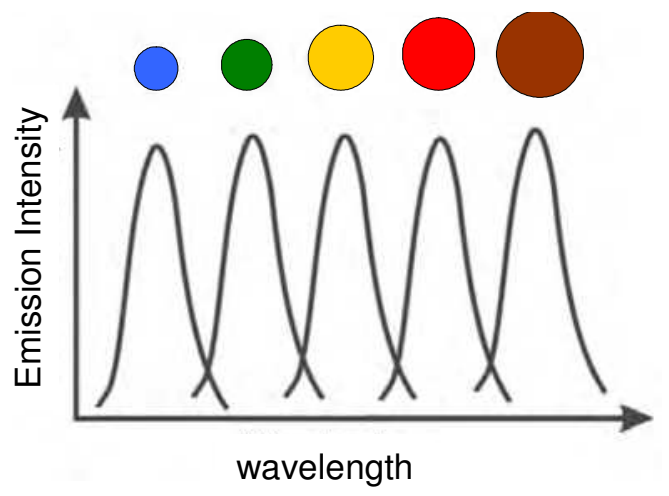

Fig. 3. Fluorescence maximum as a function of QD size (Santos et al., 2008).

In this Section we will discuss some of these important characteristics in order to promote an adequate and efficient biological application.

\subsection{General aspects about QDs-cells specific and non-specific interactions}

The cell membrane functions as a semi-permeable barrier, allowing a very few molecules to cross it while the majority of large and particulate materials are impaired. Uptake of nutrients and all communication among or between the cells and their microenvironment occur through the plasma membrane. So, understanding QD-cell membrane interactions is a very important step to develop efficient QDs for many biological applications as well as to predict and overcome any potential toxicities. These interactions depend on both the composition and environmental conditions of membranes and the chemical and physical properties of QDs themselves. QDs can interact with cells in a non-specific or specific manner. Nonspecific adsorption of QDs to the cell membranes occurs mainly by electrostatic interactions. QDs can be also delivered into the cytosol or nucleus actively by transiently 
destabilizing the cell/nuclear membrane. These active interventions include micro/ nanoinjection, electroporation and osmotic lyses. Although nonspecific binding of QDs to cell membrane has been exploited for extracellular labeling and intracellular delivery of QDs, it has become an undesirable property of QDs which impair QDs to be addressed to specific extracellular and intracellular sites.

For specific interactions a functionalizing agent intermediates the QDs and biomolecules as antibodies, proteins, nucleic acids, antigens, etc, directing them to specific targets in the cells. The process of binding the functionalizing agent to the biomolecule is called Bioconjugation. It can be accomplished by simple adsorption (of stabilizing agent such as: MPA, MSA or cysteine) to the biomolecule or by covalent attachment. The most common covalent bioconjugations occur between carboxyl-amine (trough EDC and Sulfo-NHS) groups, amineamine (by glutaraldehyde), disulfide bonds and streptavidin-biotin interactions.

The bioconjugation process is not $100 \%$ effective, so it is important to remove nonbioconjugated QDs, QDs can non-specifically bind to the cell leading to misinterpretation of the biological labeling results. There are several purification procedures to remove nonbioconjugated QDs (ex. by exclusion chromatography). Some authors also state that the coating of QDs with polyethylene glycol decrease non-specific interactions (Bentzen et al., 2005).

\subsection{Dynamic of QDs-cell interactions}

Researches have been assuming that after binding to the cell surface by specific or nonspecific interactions particles are taken up by cells through endocytosis, an energy-dependent process of internalization of macromolecules (Conner \& Schmid, 2003). Based on the size and shape of the formed vesicle, the nature of internalized material and the molecules involved, endocytosis can be divided in three endocytic pathways: phagocytosis, macropinocytosis and pinocytosis (Fig. 4). Phagocytosis is mainly conducted by specialized mammalian cells (like monocytes, macrophages and neutrophils) to engulf solid particles with diameters $>750 \mathrm{~nm}$ by the cell membranes which form internal phagosomes. Smaller particles ranging from a few to several hundred nanometers are internalized by pinocytosis or macropinocytosis, which occur in almost all cell types. In macropinocytosis and phagocytosis, large vacuoles are formed by membrane protrusions towards the material to be endocytosed. These processes are highly dependent on the actin filament polymerization. In pinocytosis, small vesicles are formed by plasma membrane invagination. Pinocytic process can be further subdivided accordingly to the participation of cytoplasmic proteins clathrin, dynamin and caveolin. Clathrin-dependent endocytosis depends on the assembly of clathrin coat from cytoplasm to the cytoplasmatic side of the forming vesicle. This process involves the participation of GTPase, dynamin and can be mediated by binding of extracellular ligands to specific receptors on the cell surface. Another kind of pinocytosis depends on the participation of both caveolin and dynamin, with formation of caveosomes. Some cargoes can be endocytosed by mechanisms that are independent of the coat protein clathrin/caveolin and the fission GTPase, dynamin. Once inside the cell, most internalized cargoes are delivered to early endosomes via vesicular (clathrin- or caveolin-coated vesicles) or tubular intermediates that are derived from the plasma membrane. Some pathways may first traffic to intermediate compartments, such glycosyl phosphatidylinositol-anchored protein enriched early endosomal compartments (GEEC), before reaching the early endosome. Fusion with early endosomes delivers molecules to acidic environment that allows recycling of some molecules to plasma membrane. The 
remaining molecules are addressed to degradation and transported to late endosome or multivesicular body (MVB) where the process of degradation performed by hydrolytic enzymes come from Golgi complex takes place. The complete degradation is finished in lysosomes (Mayor \& Pagano, 2007; De Souza et al., 2009).

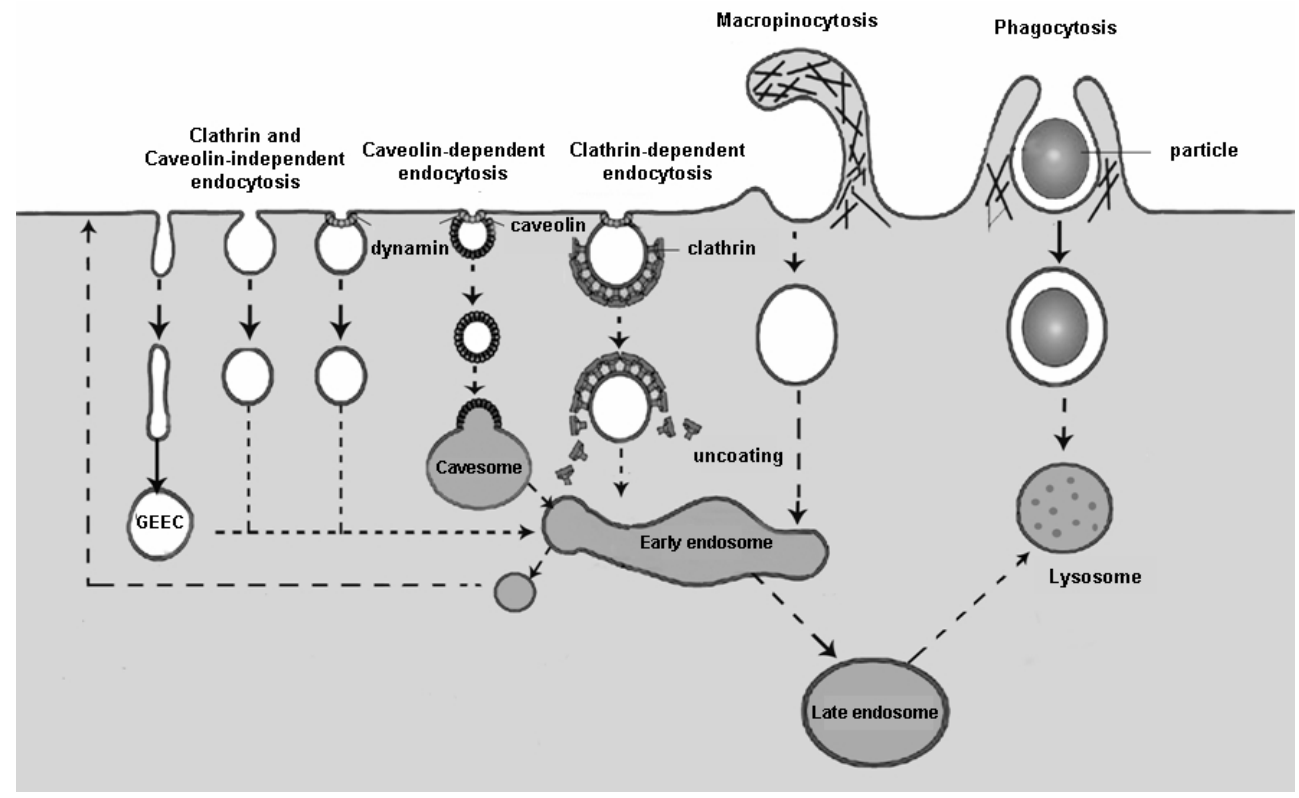

Fig. 4. Simplified scheme of endocytic pathway in mammal cells - adapted from (Mayor \& Pagano, 2007) and (De Souza et al., 2009).

It is well known that the source of QD materials and the nature of the QD surface ligand chemistry can be determinant for the intracellular fate of the nanoparticles. Typically size and shape are not the main factors that dominate the important biological process of cellular uptake of traditional matter or molecules. For most applications of nanoparticles, surface chemistry manipulations is critical for purposes like functionalization, reducing surface reactivity, reducing toxicity or enhancing chemical and optical stability.

\subsection{Intracellular delivery of free QDs}

The study of intracellular molecules and structures is still a challenge because in many cases QDs cannot reach freely the cell cytosol, limiting their application for experiments of intracellular labeling. Therefore, development of methods to cross the plasma membrane and/or escape from endo/lysosomal trapping after endocytosis is required for these purposes.

The mechanisms proposed for intracellular delivery of free QDs can generally be grouped into two categories: active and facilitated. Active delivery of QDs can be performed by microinjection and electroporation. However these methods are very invasive and often compromise the integrity of cellular structure and reduce the cellular viability (Biju et al., 2010). 
The facilitated delivery of QDs can be achieved by using peptides (such as cell-penetrating peptides, CPPs), viral vectors, some chemicals and more recently also by using liposomes (Jesorka \& Orwar, 2008). Facilitated delivery can use agents such as cationic peptide complexed to QDs that can specifically induce their internalization. However, this procedure can also result in the trapping of nanoparticles within intracellular endosomal-lysosomal systems requiring further strategies to release the sequestered material to the cytosol when other intracellular targets are desired. The treatment of cells with chemicals, such as sucrose, chloroquine or polymers, can be applied to disrupt the endosomes and liberate QDs into cytosol (Biju et al., 2010). CPPs also known as protein transduction domains (PTDs) are short peptides containing significant amounts of basic amino acids that can permeate cell membrane. CPPs, originally derived from the Tat protein of the human immunodeficiency virus type 1.1, do not require receptors or energy-dependent pathway to penetrate the membrane being an attractive tool for delivering molecules (including QDs) into cells. Delehanty et al. (2006) demonstrated that efficient cellular uptake of CdSe/ZnS by HEK 293T/17 and COS cells were achieved when polyarginine-bearing cell-penetrating peptide was self-assembled onto the QD surface via noncovalent metal-affinity interactions. These CPP-QDs complexes were trapped into endosomal/lysosomal compartments for up three days in culture. The same group has performed an extensive investigation on active delivery methods based on CPPS and concluded that these peptides are able to bypass the endocytic system. They have found that Palm1peptide was able to mediate both rapid endocytosis and a subsequent efficient cytosolic delivery of QDs conjugates 48 hours after initial exposure. The Palm-1 peptide appeared to be well tolerated with minimum toxicity (Delehanty et al., 2006, 2010).

\subsection{QDs physico-chemical aspects}

Although QDs present a broad absorption band, their application can be improved by knowing in which wavelength they can be excited to promote the highest emission intensity. A narrow first maximum band in the absorption spectrum is usually linked to a good size dispersion of the nanoparticles and a narrow (FWHM $<50 \mathrm{~nm}$ ) and intense emission spectrum is usually linked to well passivated QDs. Carboxyl coated QDs are generally very stable in basic $\mathrm{pH}$ (higher than 8.5) and in their original medium that they have been synthesized. When QDs are in contact with the biological system the $\mathrm{pH}$ is near 7.5 and the stabilizing molecules may not be all deprotonated enabling aggregation of the QDs, influencing their intracellular fate. This can lead to an unsuccessfully biological application of QDs as fluorescent probes. Moreover, some biological media can not only promote aggregation but also the quenching of QDs fluorescence. For this reason it is important to study the spectroscopic behavior of QDs in the fluids where they will be dispersed. Chemical stability in biological media can be improved, for example, by coating QDs with silica.

\subsection{General aspects of QDs toxicity}

Nanoparticle toxicity is determined by its physicochemical characteristics. Size, charge, concentration, external coating bioactivity (capping material and functional groups) and oxidative, photolytic and mechanical stability can be determinant for QDs toxicity. Several studies have suggested that the cytotoxic mechanism of QDs involve photolysis and oxidation. Under oxidative and photolytic conditions, the coating of QDs is labile and may expose potentially toxic capping materials or intact core metalloid complexes or may result in the dissolution of core metal components (e.g. Cd, Se, etc) (Li \& Chen, 2011). 
Cadmium is probably carcinogen, having a biological half-life of 15-20 years in humans. $\mathrm{Cd}^{2+}$ bioaccumulates and crosses the blood-brain barrier and placenta, and is systematically distributed to all body tissues including liver and kidney. So, If $\mathrm{Cd}^{2+}$ ions dissociate from QDs, they can be eventually toxic to the organism. QDs could be coated with inert materials, such as silica or polymers, to prevent dissociation and render Cadmium bearing QDs are less toxic compared to conventional organic dyes. Despite their potential cytotoxic effects the CdSe and CdTe QDs are the most fluorescent and for this reason are the most used QDs in life sciences. Researchers are improving the synthesis of $\mathrm{Mn}^{2+}$ doped Zinc based QDs to overcome the toxicity and to produce red emitting nanoparticles. Excitation by using UV light can also underline side effects to the cell.

Lastly it is also important to pay attention in the stabilizing agent and in osmolarity; some stabilizing agents and ionic counter ions result in unbalanced media that can lyse labile cells such as erythrocytes. Cells and biomolecules integrity also depend on the QDs $\mathrm{pH}$. When synthesis produces QDs with $\mathrm{pH}$ near $10-11$, it is necessary to reduce the $\mathrm{pH}$ to near physiological values to use QDs in live cells for keeping metabolic cell and the antibodies/antigens functions.

\section{Water dispersed QDs}

In this Section we will discuss aspects concerning to the synthesis, characterization and functionalization of QDs applied by us in the staining of parasites.

Fluorescent QDs used for biological imaging are usually obtained by colloidal synthesis involving the chemical reaction of inorganic precursors. Water colloidal synthesis typically involves three main components: inorganic precursors, organic surfactants and water. The main parameters which need to be ajusted to optimize the synthesis are: initial $\mathrm{pH}$, reaction temperature and the ratio among inorganic precursors and organic surfactants used. The surfactant helps to stabilize the nanoparticles (by preventing their aggregation) and to dissolute smaller nanocrystals in favor of larger ones. The key feature of this "bottom-up" approach is the ability to control precisely the final size of the QDs and consequently their optical properties.

\subsection{QDs synthesis}

$\mathrm{CdS} / \mathrm{Cd}(\mathrm{OH})_{2}$ nanoparticles were prepared in aqueous medium adapting the procedure described by Vossmeyer et al., 1994. In a typical procedure $\mathrm{Cd}(\mathrm{ClO})_{4}$ and $\mathrm{H}_{2} \mathrm{~S}$ were used as chemical precursors. Due to the intrinsic thermodynamically instability of colloidal suspensions, a stabilizing agent (sodium polyphosphate, $\left.\mathrm{Na}\left(\mathrm{PO}_{3}\right)_{9}\right)$ was added to the reacting system. Subsequent surface passivation with $\mathrm{Cd}(\mathrm{OH})_{2}$ was carried out to improve luminescence (Figure 5).

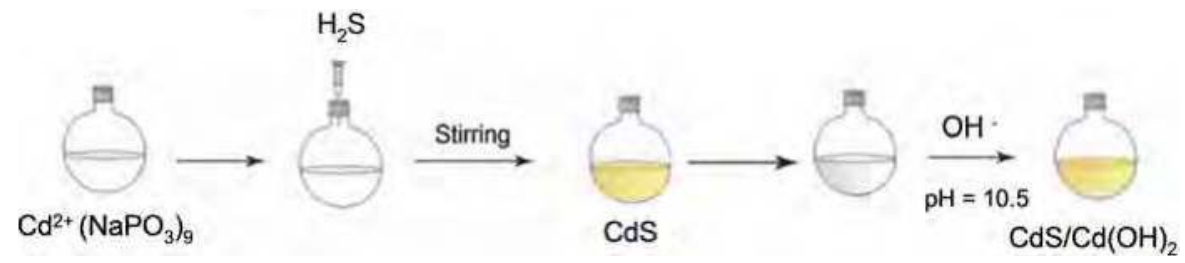

Fig. 5. Schematic illustration of $\mathrm{CdS} / \mathrm{Cd}(\mathrm{OH})_{2}$ nanoparticles synthesis. 
$\mathrm{CdTe} / \mathrm{CdS}$ nanoparticles were synthesized according to the previously reported methodology (Santos, 2008). Briefly, QDs were prepared by the addition of Te2- solution in a $\mathrm{Cd}\left(\mathrm{ClO}_{4}\right)_{2} 0.01 \mathrm{M}$ solution of $\mathrm{pH}$ above 10 in the presence of MPA (mercaptopropionic acid) or MSA (mercaptosuccinic acid) as stabilizing agents in a 2:1:6 ratio for Cd:Te:MPA and 2:1:2.4 of Cd:Te:MSA. The reaction proceeds under constant stirring and heating of $80^{\circ} \mathrm{C}$ in argon or nitrogen (White Martins). The $\mathrm{Te}^{2-}$ solution was prepared using metallic tellurium and $\mathrm{NaBH}_{4}$, under argon or nitrogen saturated inert atmosphere. At the end of the reaction, the colloidal dispersion showed a brownish color (Figure 6). The CdTe passivation shell is composed of a few monolayers of CdS grown during the post heating of the suspensions and monitored by the increase of the fluorescence intensity. The CdTe/CdS-MSA QDs were synthesized in PBS (Phosphate Buffered Saline) to improve biocompatibility.

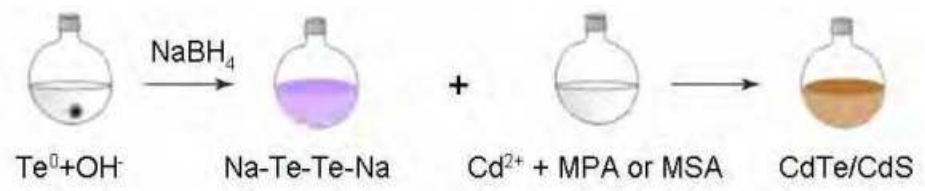

Fig. 6. Schematic illustration of the CdTe/CdS nanocrystals synthesis.

\subsection{QDs structural characterizations}

QDs structural properties were obtained by using Transmission Electron Microscopy (TEM) and X-ray Diffraction analysis (Figure 7). Samples for the microscopic analysis were prepared by drying a drop of the diluted colloidal suspension on a copper grid coated with carbon/formwar film. X-ray analysis of all QD employed show that they presented a cubic zinc blend phase structure.

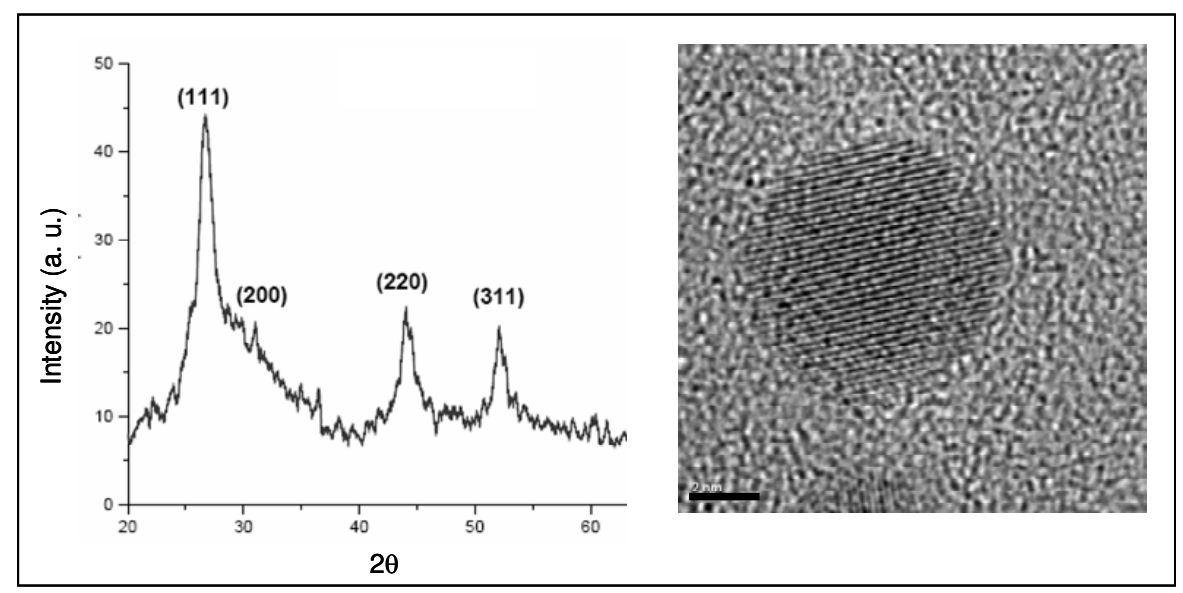

Fig. 7. A representative $\mathrm{X}$-ray powder diffraction profile and TEM image of the $\mathrm{CdS} / \mathrm{Cd}(\mathrm{OH})_{2}$ QDs $($ bar $=2 \mathrm{~nm})$.

By using the Scherrer formula, we can calculate the QDs mean diameters from the width of the most intense diffraction peak at half-maximum. The values obtained by $\mathrm{X}$-ray diffraction 
were in accordance with TEM data for both QDs. According to these analysis, CdS/ Cd $(\mathrm{OH})_{2}$ QDs have a mean diameter of $10 \mathrm{~nm}$ (Figure 7), CdTe/CdS-MPA QDs of $2.7 \mathrm{~nm}$ (Figure 8) and similarly CdTe/CdS-MSA QDs of $3.2 \mathrm{~nm}$ (data not shown).

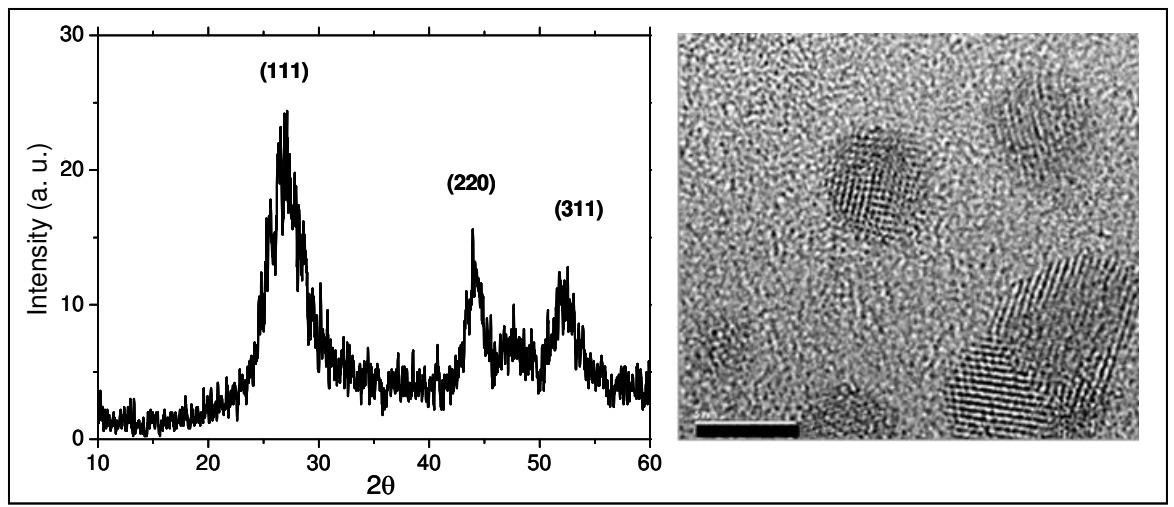

Fig. 8. A representative $X$-ray powder diffraction profile and TEM image of the CdTe/CdS QDs (bar $=3 \mathrm{~nm})$.

\subsection{QDs optical characterizations}

Figures 9 and 10 present the absorption and emission spectra of $\mathrm{CdS} / \mathrm{Cd}(\mathrm{OH})_{2}$ and $\mathrm{CdTe} / \mathrm{CdS}-\mathrm{MPA}$ QDs. The $\mathrm{CdS} / \mathrm{Cd}(\mathrm{OH})_{2}$ shows maximum absorption at $475 \mathrm{~nm}$. The mean diameter of CdS can be directly related to the value of the first maximum absorption wavelength. In $475 \mathrm{~nm}$ it was described a size of about $9.6 \mathrm{~nm}$ (Vossmeyer et al., 1994). This synthesis provided around $1.0 \times 10^{13}$ particles $/ \mathrm{mL}$. The mean diameters for CdTe/CdSMPA and CdTe/CdS- MSA are respectively $2.7 \mathrm{~nm}(\lambda=286 \mathrm{~nm})$ and $3.5 \mathrm{~nm}(\lambda=597 \mathrm{~nm})$, also estimated using the spectrum first absorption maximum (Dagtepe et al., 2007). The

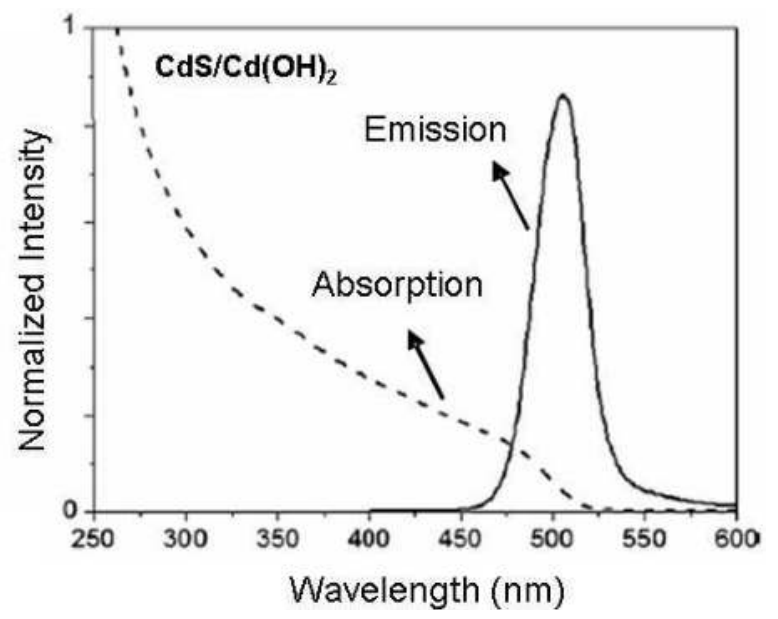

Fig. 9. Absorption and emission spectra of the $\mathrm{CdS} / \mathrm{Cd}(\mathrm{OH})_{2}$ - Polyphosphate QDs. 
number of particles was $1.3 \times 10^{15}$ particles/mL for CdTe/CdS-MPA and $5.6 \times 10^{14}$ particles/mL for CdTe/CdS-MSA (Yu et al., 2003). The mean diameters obtained by optical characterization are in accordance to the structural analysis.

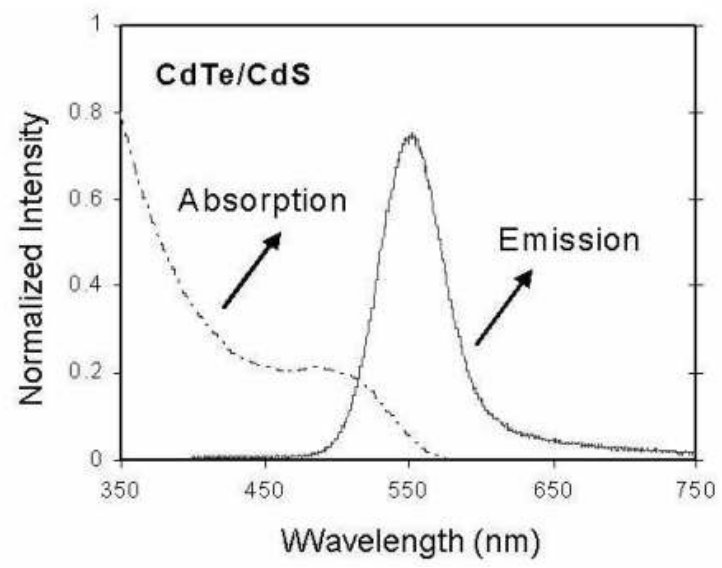

Fig. 10. Absorption and emission spectra of the CdTe/CdS-MPA QDs.

The emission band profile shows a maximum at $506 \mathrm{~nm}$ for $\mathrm{CdS} / \mathrm{Cd}(\mathrm{OH})_{2} \mathrm{QDs}, 550 \mathrm{~nm}$ for CdTe/CdS-MPA QDs and $600 \mathrm{~nm}$ for CdTe/CdS-MSA QDs respectively. These CdTe/CdSMPA showed intense luminescence after 3 hours of refluxing process at $80^{\circ} \mathrm{C}$ and MSA after 7 hours. This heat treatment process, at high $\mathrm{pH}$, promotes the hydrolysis of the MPA/MSA acid molecules releasing thiol group ( $\left.\mathrm{SH}^{-}\right)$which help to grow the passivation shell (Gaponik \& Rogach, 2010). CdS/Cd(OH $)_{2}$ QDs presents final $\mathrm{pH}$ around 8.0 while $\mathrm{CdTe} / \mathrm{CdS}$ QDs presents final $\mathrm{pH}$ equal to 10.5 .

\subsection{QDs preparation for applications}

For application of QDs with biological systems, $1400 \mu \mathrm{L}$ of the $\mathrm{CdS} / \mathrm{Cd}(\mathrm{OH})_{2}$ nanoparticles $\left(1 \times 10^{13}\right.$ particles/ml) were functionalized with $100 \mu \mathrm{L}$ PEG-1000 $(0.0025 \mathrm{~g} / \mathrm{mL})$ in physiological medium. PEG is a water-soluble biocompatible polymer which possesses a low degradation rate and is commonly used to prevent the close contact of nanometric drug carrier systems with enzymes and other molecules present in the biological systems. The PEGylation of the particles is believed to decrease the cytotoxicity of the QDs allowing in vitro analysis of live cells for longer time periods (Chaves et al., 2008).

The CdTe/CdS QDs were used without further bioconjugation. The MPA and MSA were used to promote the interactions between QDs and parasites.

\section{Trypanosomatides}

Protozoa of the Trypanosomatidae family are agents of parasitic disease that have a high incidence of occurrence with major negative economic impact on developing countries. Trypanosoma cruzi, the ethiologic agent of Chagas disease, is transmitted to human beings by either blood sucking triatomine insect vectors, blood transfusion, organ transplantation or 
congenital transmission. This disease is present in 18 tropical countries and has affected 17 million individuals. The life cycle of $T$. cruzi involves the obligatory passage through the vertebrate (mammals) and invertebrate (triatomine insects) hosts. Shortly after infection the individuals enter the acute phase of illness, which can extend for weeks or even months, being typically asymptomatic or associated with fever and other less specific clinical manifestations. In the absence of a specific treatment the rate of deaths associated to Chagas disease ranging from 10 to $15 \%$ and 10 to $50 \%$ of survivors evolve into a chronic phase, which is characterized by a potentially fatal cardiomyopathy, megaesophagus or megacolon ${ }^{1}$.

In the case of Leishmaniasis, caused by different species of protozoa belonging to the Leishmania genus, about 16 million people are infected in Africa, Asia, parts of Europe and Latin America. Leishmaniasis is a poverty-related disease. It affects the poorest people and is associated with malnutrition, displacement, poor housing, illiteracy, gender discrimination, weakness of the immune system and lack of resources. Depending on the parasite species and immunologic response of host the disease can assume a wide range of clinical symptoms, which may be cutaneous, mucocutaneous or visceral. Cutaneous leishmaniasis is the most common form whereas visceral leishmaniasis is the most severe form, in which vital organs of the body are affected ${ }^{2}$.

Trypanosomatides parasites are usually transmitted by insect vectors and invade a range or different tissues or cell types in mammalian These parasites undergo a number of distinct developmental and morphological changes during their complex life cycles in the insect vector and mammalian hosts (Figure 11).

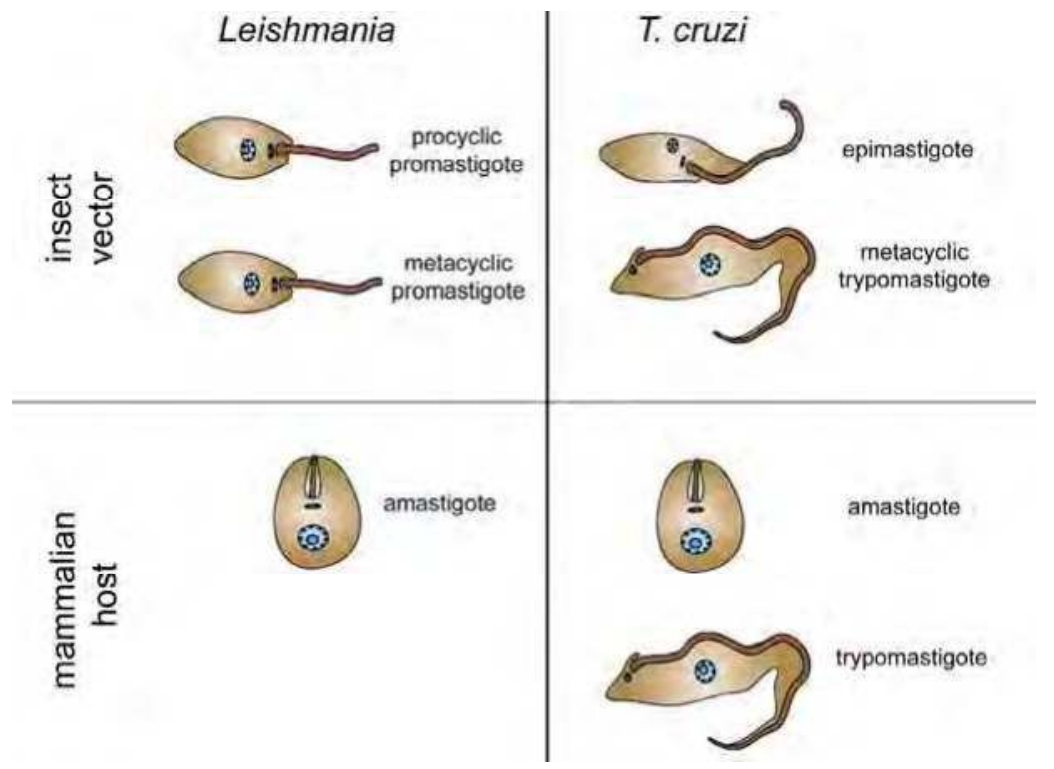

Fig. 11. Developmental stages of T. cruzi and Leishmania spp. during the life cycle in the vertebrate and invertebrate hosts.

${ }^{1}$ http://www.fiocruz.br/chagas_eng/cgi/cgilua.exe/sys/start.htm?tpl=home

${ }^{2}$ http://www.who.int/leishmaniasis/en/ 
In view of the importance of Trypanosomatides some efforts have been devoted to understand the interactions existing between the parasites and their hosts. In this way, several fluorescent probes, as acridine orange, Nile red, and GFP-transfected cells have been used for T. cruzi and Leishmania morphological and physiological characterization (Pereira et al., 2011; Monte Neto et al., 2010).

However, the organic fluorophores have limited use in live cells due to their instability, photobleaching effects and potential photocytotoxicity. In order to benefit from the advantageous optical properties of QDs as in vivo and in vitro probes for biological studies in these parasites, some issues must be addressed. Firstly: how do the parasites interact with different kind of QDs? How are they taken up by the parasites? Once inside the cell what is their intracellular fate? And finally, how are the QDs eliminated? Before discussing these questions we will briefly describe some particularities of the cell biology and the endocytic pathway of T. cruzi and Leishmania.

It is well established that to enter the cell and achieve their intracellular target QDs must first interact with the plasma membrane. The way by which QDs interact with the parasite surface is therefore crucial to determine their intracellular fate inside the cell.

Trypanosomatides are high polarized cells with organelles placed in specific regions of the cytoplasm. Although Trypanosomatides are similar in some aspects of endocytosis, they diverge as the structural organization of their endocytic pathways. The surface of all Trypanosomatides is composed by a functional assembly of two components: the plasma membrane and a stable corset of subpelicular microtubules connected with each other and with plasma membrane by short filaments. This arrangement forms a rigid structure that impairs endocytic vesicles to form along the whole parasite body. In Leishmania species the uptake of macromolecules is performed exclusively throughout the flagellar pocket, which is a plasma membrane invagination that is devoid of microtubules. Besides the flagellar pocket a highly specialized structure known as the cytostome is also involved in the ingestion of macromolecules in epimastigote forms of T. cruzi. The cytostome, present only in epimastigote and amastigote forms, is considered as the main site of endocytosis in epimastigotes but their functions in amastigotes is still unknown. In epimastigotes the cytostome is located near the flagellar pocket and extends deeply into the cytoplasm as a narrow tubule (the cytopharynx) that finishes in a dilatation from where endocytic vesicles pinch off.

The endocytic pathway of Leishmania promastigotes comprises at least three morphologically distinct compartments: a network of tubular endosomes that are localized near the flagellar pocket; a population of multivesicular bodies that are also located near the anterior end of promastigotes and an unusual multivesicular tubule (MVT)-lysosome that runs along the anterior-posterior axis of the parasite. It has been proposed that MVTs are the sites of accumulation of the protein and lipid that are ingested by the parasite and the final compartment of endocytic pathway in this evolutive form. The intracellular amastigote forms of Leishmania escape from host cell immune cell response by infecting macrophages. Intracellular amastigote are able to ingest macromolecules through the flagelar pocket which has access to the parasitophorous vacuole. This process seems to be mediated by clathrin molecules. The ingested material is degraded in the megasomes, large membranebounded structures with acidic environment. Megasomes are thought to be the lysosomal compartment of amastigotes (De Souza et al., 2009). 
As mentioned above T. cruzi endocytosis only occurs in the epimastigote forms. Low or lacking of endocytic activity can be observed in trypomastigote (the infective form of parasite) and amastigotes (the intracellular forms). Following binding to the cytostome and flagellar pocket, macromolecules are rapidly internalized in small uncoated vesicles which bud from these structures. The characterization of endocytic compartments in $T$. cruzi is still controversial (Porto-Carreiro et al., 2000; Figueiredo \& Soares, 2000). However, there is a consensus that the endocytic pathway seems to converge to large lysosomerelated organelles called reservosomes. The reservosome has a protein electrodense matrix were small lipid inclusions are immersed. These organelles have been implicated mainly in macromolecule storage and degradation, although other important roles in the life cycle of parasite, as cell differentiation, autophagy and recycling processes have been also demonstrated (Figueiredo et al., 2004; Soares et al., 1992).

\section{QDs applications for bioimaging of trypanosomatides}

In this Section we will present some results obtained by our research group on the applications of CdS/ $\mathrm{Cd}(\mathrm{OH})_{2}$ and CdTe/CdS water dispersed QDs in bioimaging of Trypanosoma cruzi and Leishmania amazonensis. We have successfully demonstrated that different QDs can be efficiently used as fluorescent probes for bioimaging of live Trypanosomatides.

The amount of $250 \mu \mathrm{L}$ of live epimastigote forms of T. cruzi $\left(1.0 \times 10^{6}\right)$ were incubated at room temperature with $350 \mu \mathrm{L}$ of colloidal CdS/Cd(OH $)_{2}-\mathrm{PEG}$ QDs suspension $\left(1 \times 10^{13}\right.$ particles/mL) for 180 minutes using Hank's solution (Invitrogen, USA). The choice of salt balanced Hank's solution as incubation medium was due to the fact that the medium commonly used for axenic cultivation of parasites suppresses the fluorescence of $\mathrm{CdS} / \mathrm{Cd}(\mathrm{OH})_{2}$ QDs. This probably happens because $\mathrm{Cd}(\mathrm{OH})_{2}$ is a labile passivation shell. The Hank's solution has physiological $\mathrm{pH}$ (7.5) and keeps the parasites alive with minimum interference in the fluorescence signal.

Figure 12 shows fluorescence microscopy and transmission electron microscopy images of $T$. cruzi labeled with CdS/ Cd(OH $)_{2}$. It is possible to observe that QDs entered the cytostome and could be further detected in small vesicles and finally in large compartments, which probably correspond to the reservosomes. As mentioned above the cytostome is the main site of receptor-mediated endocytosis in T. Cruzi (Figure 12 a). Previous studies demonstrated that proteins coupled to colloidal gold are efficiently endocytosed through the cytostome by a receptor-mediated mechanism. Vesicles pinch off from the bottom of these structures delivering their cargo directly into reservosomes (Figueiredo et al., 2004; Figueiredo \& Soares, 2000). It seems that the endocytosis of PEG-CdS/Cd(OH $)_{2}$ shares the same pathway.

An interesting advantage of QDs at biological point of view is that these particles are nanocrystals with high atomic number atoms (Cadmium, Tellurium, etc). It means that they are electron-dense and can be visualized by transmission electron microscopy (Figure $12 \mathrm{~b}$ ). This feature is extremely useful considering that besides provide high quality fluorescence images QDs also allow the visualization and localization of particles at ultrastructural level. The transmission electron microscopy analysis of epimastigote incubated with $\mathrm{CdS} / \mathrm{Cd}(\mathrm{OH})_{2}$ corroborates the data obtained from fluorescence microscopy, showing a high concentration of QDs in endocytic vesicles and in tubules resembling cytosomes which are in close association with reservosomes (Figure $12 \mathrm{c}$ ). Additionally, the parasite had a well-preserved ultrastructure. All the data collected suggest that QDs are a useful tool for the bioimaging of T.cruzi. 


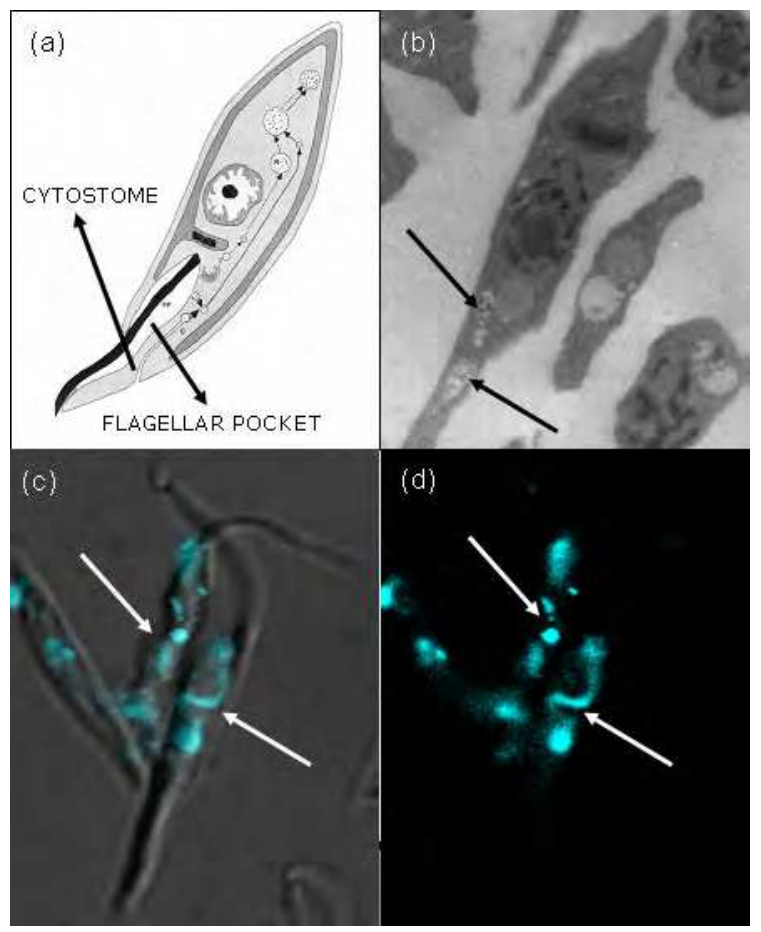

Fig. 12. (a) Endocytic pathway of T. cruzi epimastigote. Nutrients are taken up through the cytostome and the flagellar pocket and delivery into large membrane-bound structures, the reservosomes. (b) TEM of T. cruzi parasites showing the accumulation of $\mathrm{CdS} / \mathrm{Cd}(\mathrm{OH})_{2}-$ PEG QDs (arrow) inside the tubular structure resembling the cytostome in close association with reservosomes. (c) Overlay of the image of fluorescence microscopy and differential interference contrast showing the strong QDs labeling in the cytostome. (d) The same image showing only fluorescence staining. Note the accumulation of tracer at the bottom of the cytostome (arrow). Excitation at $456 \mathrm{~nm}$ (Chaves et al., 2008).

The analysis of T. cruzi by using fluorescent QDs can clarify the comprehension of the endocytic process as well as to clarify the cellular differentiation mechanism. Moreover, the images preserve the original fluorescence emission wavelength suggesting that the PEG layer protects the QDs passivation shell that can induce deactivation processes and loss of fluorescence. The chemical and optical stability of this inorganic-organic assembly inside the biological system show its great potential as functional fluorescent nanoprobes.

CdTe/CdS-MAA and CdSe/CdS-MAA nanocrystals were also used by other research groups to study T. cruzi-insect vector interactions (Feder et al. 2009). These QDs were synthesized by using mercaptoacetic acid (MAA). QDs were also conjugated with lectins to label specific carbohydrates involved in parasite-vector interaction. In this work parasites and intestinal cells were labeled with both green-emitting CdTe/CdS-MAA and yellowemitting CdSe/CdS-MAA QDs. Parasites were maintained viable up to three day in culture medium containing of QDs. In experiments using QDs conjugated to Sambucus nigra lectin (SNA), which specifically bind to galactose and $\mathrm{N}$-acetylgalactosamine carbohydrates 
residues, labeling was found in intracellular vesicles. So, it is likely that SNA-QDs conjugates are recognized by specific receptors at the parasite surface before to be interiorized in endocytic vesicles. No fluorescence could be detected in the cytostome suggesting that the chemical characteristic of QDs as well as their bioconjugation to specific ligands have influence in the uptake of these nanoparticles.

The quantity of $300 \mu \mathrm{L}$ of $\mathrm{CdS} / \mathrm{Cd}(\mathrm{OH})_{2}$ QDs (at $1 \times 10^{13}$ particles/mL) was also used by us to label $L$. amazonensis live parasites $\left(100 \mu \mathrm{L}-2 \times 10^{5}\right.$ cells $\left./ \mathrm{mL}\right)$. Figure 13 shows the analysis of these parasites by fluorescence microscopy.

The living parasites showed no signal of damage after the incubation procedure and maintained their morphological integrity and viability even after 18 hours of incubation, demonstrating the isotonicity of the labeling procedure as well as the low toxicity of the QDs. The emission pattern (Figure 13 a and c), observed under $456 \mathrm{~nm}$ excitation, evidenciates the labeling of different internal structures present in the promastigote: nucleus, kinetoplast (specialized region of parasite mitochondria where the mitochondrial DNA, named k-DNA, is concentrated) and flagellar pocket (Figure $13 \mathrm{~b}$ ). Contrary to Trypanosoma cruzi, no labeling in intracellular vesicles and in endocytic structure could be detected and the mechanism of uptake and delivery of QDs in nucleus and kinetoplast is still unknown. Further experiments will be conducted to better understand the routes of internalization and interaction of QDs-parasite.

We have also reported the labeling of L. amazonensis live parasites using CdTe/CdS with MPA and MSA agents that have carboxyl groups available.

The quantity of $350 \mu \mathrm{L}$ of CdTe/CdS-MPA (at $1.3 \times 10^{15}$ particles $/ \mathrm{mL}$ ) was incubated for 30 minutes with $250 \mu \mathrm{L}$ of L. amazonensis live parasites $\left(2.0 \times 10^{5}\right)$. For the CdTe/CdS-MSA a similar procedure was applied by using $100 \mu \mathrm{L}$ of cells and $300 \mu \mathrm{L}$ of QDs $\left(5.6 \times 10^{14}\right.$ particles $/ \mathrm{mL}$ ), in this experiment cells were incubated for 90 minutes.
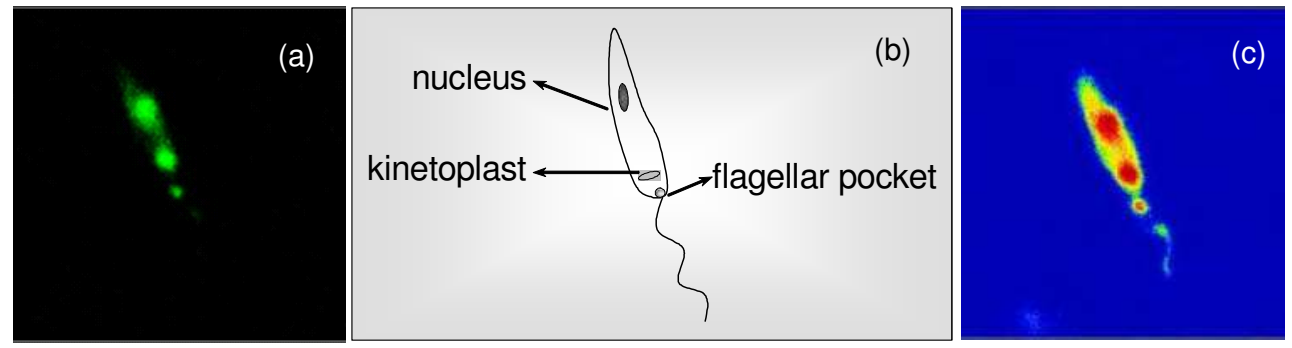

Fig. 13. (a) Confocal image of L. amazonensis promastigote labeled with $\mathrm{CdS} / \mathrm{Cd}(\mathrm{OH})_{2}$ QDs excited at $456 \mathrm{~nm}$. (b) The Figure shows a schematic representation of a L. amazonensis promastigote parasite, showing three different internal structures, the nucleus, the kinetoplast and the flagellar pocket (c) Corresponding fluorescence intensity maps - blue represents the absence of fluorescence and red the highest intensity.

Incubation of parasites with CdTe/CdS-MPA QDs or CdTe/CdS-MSA showed a similar labeling pattern of $\mathrm{CdS} / \mathrm{Cd}(\mathrm{OH})_{2}$ QDs with strong labeling of flagellar pocket and nucleus (Figure 14 a). These results suggest that carboxylic groups of the stabilizing and functionalizing agents (present on the QDs surface) were responsible for non specific interaction with proteins in cells. 

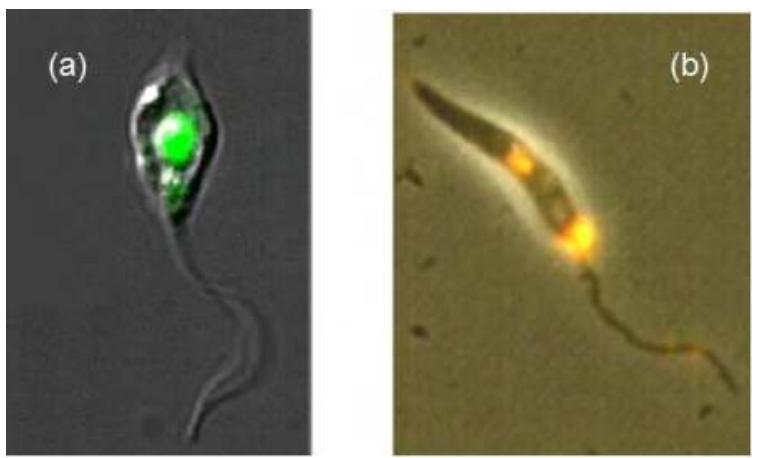

Fig. 14. (a) Confocal and (b) conventional fluorescence microscope images of the $L$. amazonensis incubated with CdTe/CdS-MPA (a) and CdTe/CdS-MSA (b).

When a study aims the labeling of live cells as T. cruzi, the potential cytotoxicity of QDs is an important issue to be addressed. We followed the growth and viability of epimastigote forms incubated with $\mathrm{CdS} / \mathrm{Cd}(\mathrm{OH})_{2}$ for 96 hours of cultivation, by light microscopy. T. cruzi epimastigotes were grown at $28^{\circ} \mathrm{C}$ in liver infusion tryptose medium supplemented with $10 \%$ bovine fetal serum (Chiari \& Camargo, 1984; Jaffe et al., 1984). In order to determine the effect of QDs on viability and growth, T. cruzi epimastigotes $\left(1 \times 10^{6} / \mathrm{mL}\right)$ were incubated at different $\mathrm{CdS} / \mathrm{Cd}(\mathrm{OH})_{2}$ QDs concentrations and cell density was estimated by directly cell counting in a hemocytometric chamber. Our results showed that no significant difference in the parasite growth and viability could be detected at 24 hours of incubation with QDs at any concentration tested. However, after 48 hours of cultivation the number of parasites decreases in a time and concentration dependent manner (Figure 15).

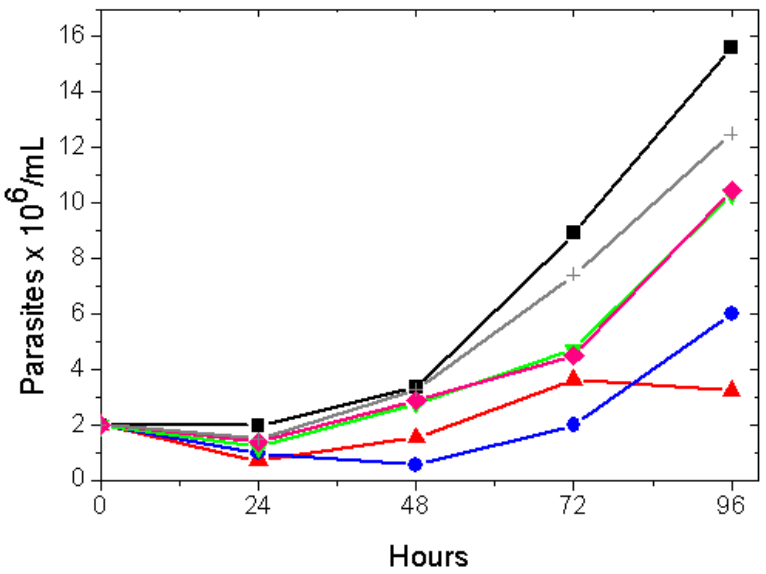

Fig. 15. Effects of CdS/Cd(OH $)_{2}$ QDs on T. cruzi growth. (घ) Control; $(\boldsymbol{\Delta}) 0,5 \times 10^{13} ;(\bullet) 2,5 \times$ $10^{12} ;(\boldsymbol{\nabla}) 2,5 \times 10^{11} ;(\bullet) 2,5 \times 10^{9} ;(\mathbf{X}) 2,5 \times 10^{7}$ particles $/ \mathrm{mL}$.

Similarly, Vieira et al., 2011 analyzed the nanotoxic effects of CdTe/CdS-MAA QDs in T. cruzi. These authors found that high doses of QDs $20 \mu \mathrm{M}$ and $200 \mu \mathrm{M} / \mathrm{mL}$ led to a decrease of T. cruzi growth patterns. Contrary, low concentrations of CdTe/CdS-MAA QDs did not 
affect parasite integrity, division and motility up to seven days of culture in presence of QDs. Transmission electron microscopy demonstrated that CdTe/CdS-MAA intracellular localization differs significantly from those found for $\mathrm{CdS} / \mathrm{Cd}(\mathrm{OH})_{2}$. CdTe/CdS-MAA labeling was present in cytoplasmic vesicles and near reservosomes, but not inside this latter organelle, suggesting that different mechanisms mediate the uptake and accumulation of $\mathrm{CdS} / \mathrm{Cd}(\mathrm{OH})_{2}$ and CdTe/CdS-MAA in this parasite. Since the QDs were also detected at the plasma membrane a mechanism for elimination of these nanoparticles could be through the fusion of intracellular vesicle containing CdTe to plasma membrane for shedding and elimination (Vieira et al., 2011).

\section{General conclusions}

In summary, our results have shown the possibility of applying fluorescent QDs as probes to label living T. cruzi and Leishmania and to study cellular processes in these parasites. Even though QDs have been presented as fluorescent probes in the late 90's they are not yet conventional probes. There are still some important aspects to consider, specially those related to the maintenance of their optical properties and chemical stability in contact with the biological systems. Beyond the great optical properties of this inorganicorganic ensemble, QDs are electron-dense and can also be explored at ultrastructural level. This feature helps the monitoring of the cellular uptake of QDs and their intracellular fate. The investigation of QDs-trypanosomatides interactions can lead to a better comprehension of the endocytic routes providing new insights of the parasites cellular biology, which can help to understand the cellular mechanisms involved in the Chagas disease and Leishmaniasis.

\section{Acknowledgement}

The authors are grateful to CAPES, CNPq, FACEPE, HEMOPE, L'óreal, Brazilian Academy of Sciences and UNESCO. This work is also linked to the National Institute of Photonics.

\section{References}

Barroso, M. M. (2011) Quatum dots in cel biology. J Histochem Cytochem., Vol. 59, pp. 237-251.

Bentzen, E. L.; Tomlinson, I. D.; Mason, J.; Gresch, P.; Warnement, M. R.; Wright, D.; Sanders-Bush, E.; Blakely, R. \& Rosenthal, S. J. (2005). Surface Modification To Reduce Nonspecific Binding of Quantum Dots in Live Cell Assays. Bioconjugate Chem., Vol. 16, pp. 1488-1494.

Biju, V.; Itoh, T. \& Ishikawa, M. (2010). Delivering quantum dots to cell: bioconjugated quantum dots for target and nonspecific extracellular and intracellular imaging. Chem. Soc. Rev., Vol. 39, pp. 3031-3056.

Conner, S. D. \& Schmid, S. L. (2003). Regulated portals of entry into the cell. Nature, Vol. 422, pp. $37-44$.

Chaves, C. R.; Fontes, A.; Farias, P. M. A.; Santos, B.S.; Menezes, F.D.; Ferreira, R. C.; César, C. L. César, Galembeck, A. \& R.C.B.Q. Figueiredo. (2008). Application of core-shell PEGylated CdS/Cd(OH $)_{2}$ quantum dots as biolabels of Trypanosoma cruzi parasites. Applied Surface Science, Vol. 225, pp. 728-730. 
Chiari, E. \& Camargo, E. P. (1984). Culturing and cloning of Trypanosoma cruzi. Genes and antigens of parasites, A laboratory manual, (2a ed), In Morel CM, Fundação Oswaldo Cruz, Rio de Janeiro, p. 23-26.

Dagtepe, P.; Chikan, V.; Jasinski, J. \& Leppert, V. J. (2007). Quantized Growth of CdTe Quantum Dots, Observation of Magic-Sizes CdTe Quantum Dots. Journal of Physical Chemistry, Vol. 111, pp. 14977-14983.

De Souza, W.; SantAnna, C.; Cunha-e-Silva, N. L. \& Narcisa, L. (2009). Electron microscopy and cytochemistry analysis of the endocytic pathway of pathogenic protozoa. Progess in Histochemistry and Cytochemistry. Vol. 44, pp. 67-124.

Delehanty, J. B.; Medintz, I. L.; Pons, T.; Dawson, P. E,; Brunel, F. M.; Mattoussi, H. (2006). Self-assembled quantum dot-peptide bioconjugates for selective intracellular delivery. Bioconjugate Chem., Vol. 17, pp. 920-927.

Delehanty, J. B.; Bradburne, C. E.; Boeneman, K.; Susumu, K.; Farrell, D.; Mei, B. C.; BlancoCanosa, J. B.; Dawson, G.; Dawson, P. E.; Mattoussi, H. \& Medintz, I. L. (2010). Delivering quantum dot-peptide bioconjugates to the cellular cytosol: escaping from the endolysosomal system. Integr Biol (Camb), Vol. 2, pp. 265-277.

Feder, D.; Gomes, S. A.; de Thomaz, A. A.; Almeida, D. B.; Faustino, W. M.; Fontes, A.; Stahl, C. V.; Santos-Mallet, J. R. \& César, C. L. (2009). In vitro and in vivo documentation of quantum dots labeled Trypanosoma cruzi--Rhodnius prolixus interaction using confocal microscopy. Parasitol Res., Vol. 106, pp. 85-93.

Figueiredo, R. C. \& Soares, M. J. (2000). Low temperature blocks fluid-phase pinocytosis and receptor-mediated endocytosis in Trypanosoma cruzi epimastigotes. Parasitol Res., Vol. 86, pp. 413-418.

Figueiredo, R. C.; Rosa, D. S.; Gomes, Y. M.; Nakasawa, M.; Soares, M. J. (2004). Reservosome: an endocytic compartment in epimastigote forms of the protozoan Trypanosoma cruzi (Kinetoplastida: Trypanosomatidae). Correlation between endocytosis of nutrients and cell differentiation. Parasitology, Vol. 129, pp. 431-438.

Gaponik, N.; Rogach, A. (2010). L.Thiol-capped CdTe nanocrystals: progress and perspectives of the related research fields. Phys. Chem. Chem. Phys., Vol. 12, pp. 8685-8693.

Giepmans, B. N. G.; Adams, S. R.; Ellisman, M. E. \& Tsien, R. Y. (2006). The Fluorescent Toolbox for Assessing Protein Location and Function. Science, Vol. 312, pp. 217-224.

Jaffe, C. L.; Grimaldi, G.; McMahon-Pratt, D. (1984). The cultivation and cloning of Leishmania. Genes and antigens of parasites. A laboratory manual, 2nd ed., In Morel CM, Fundação Oswaldo Cruz, Rio de Janeiro, p. 48-91.

Jesorka, A.; Orwar, O. (2008). Liposomes: Technologies and Analytical Applications. Annu. Rev. Anal. Chem. Vol. 1, pp. 801-32.

Kelf, T. A.; Sreenivasan, V. K. A.; Sun, J.; Kim, E. J.; Goldys, E. M. \& Zvyagin, A. V. (2010). Non-specific cellular uptake of surface-functionalized quantum dots. Nanotechnology, Vol. 21, pp. 1-8.

Li, Yu-Feng \& Chen, C. (2011). Fate and Toxicity of Metallic and Metal-Containing Nanoparticles for Biomedical Applications. Small, pp. 1-16.

Mayor, S. \& Pagano, R. E. (2007). Pathways of clatrin-independent endocytosis. Nature Reviews Molecular Cell Biology, Vol. 8, pp. 603-612.

Michalet, X.; Weiss, S. \& Jäger, M. (2006). Single-Molecule Fluorescence Studies of Protein Folding and Conformational Dynamics. Chemical Reviews, Vol. 106, pp. 1785-1813. 
Monte Neto, R. L.; Sousa, L. M.; Dias, C. S.; Barbosa Filho, J. M.; Oliveira, M. R. \& Figueiredo, R. C. (2010). Morphological and physiological changes in Leishmania promastigotes induced by yangambin, a lignan obtained from Ocotea duckei. Exp Parasitol., Vol. 127, pp. 215-221.

Pereira, M. G.; Nakayasu, E. S.; Sant'Anna, S.; De Cicco, N. N. T.; Atella, G. T.; De Souza, W. Almeida, I. C. \& Cunha-Silva, N. (2011). Trypanosoma cruzi epimastigotes are able to store and mobilize high amounts of cholesteral in reservossome lipid inclusions. PLOS One, Vol. 6, pp. 222359.

Porto-Carreiro, I.; Attias, M.; Miranda K.; De Souza, W.; Cunha-e-Silva, N. (2000). Trypanosoma cruzi epimastigote endocytic pathway: cargo enters the cytostome and passes through an early endosomal network before storage in reservosomes. European Journal of Cell Biology. Vol. 79, pp. 858-869.

Samia, A. C. S., Dayal, S. \& Burda, C., 2006. Quantum Dot-based Energy Transfer: Perspectives and Potential for Applications in Photodynamic Therapy. Photochemistry and Photobiology, Vol. 82, pp. 617-625.

Santos, B. S.; Farias, P.M.A. Farias \& Fontes, A. (2008). Semiconductor Quantum Dots for Biological Applications. Handbook of Self Assembled Semiconductor Nanostructures for Novel Devices in Photonics and Electronics. pp. 773-799.

Say, R.; Kiliç, G. A.; Ozcan A. A,; Hür, D.; Yilmaz, F.; Kutlu, M.; Yazar, S.; Denizli, A.; Diltemiz, S. E. \& Ersöz, A. (2011). Investigation of photosensitively bioconjugated target quantum dots for labeling of $\mathrm{Cu} / \mathrm{Zn}$ superoxide dismutase in fixed cel and tissue sections. Histochem Cell Biol., Vol. 135, pp. 523-530.

Soares, M. J.; Souto-Padrón, T.; De Souza, W. (1992). Identification of a large pre-lysosomal compartment in the pathogenic protozoon Trypanosoma cruzi. J Cell Sci., Vol. 102, pp. 157-167.

Tian, J., Liu, R., Zhao, Y., Peng, Y., Hong, X., Xu, Q. \& Zhao, S. (2010). Synthesis of $\mathrm{CdTe} / \mathrm{CdS} / \mathrm{ZnS}$ quantum dots and their application in imaging of hepatocellular carcinoma cells and immunoassay for alpha fetoprotein. Nanotechnology, Vol. 21, pp. 1-8.

Vieira, C. S.; Almeida, D. B.; Thomaz, A. A.; Menna-Barreto, R. F. S; Santos-Mallet, J. R; Cesar, C. L.; Gomes, S. A. O. G; Feder, D. (2011). Studying nanotoxic effects of CdTe quantum dots in Trypanosoma cruzi. Mem Inst Oswaldo Cruz, Rio de Janeiro, Vol. 106, pp. 158-165.

Vossmeyer, T.; Katsikas, L.; Giersig, M.; Popovic, IG, Diesner, K.; Chemseddine, A.; Eychmüller, A.; Weller, H. J. (1994). CdS Nanoclusters: Synthesis, Characterization, Size Dependent Oscillator Strength, Temperature Shift of the Excitonic Transition Energy, and Reversible Absorbance Shift. The Journal of Physical Chemistry, Vol. 98, pp. 7665.

Yezhelyev, M. V., Gao, X., Xing, Y., Al-Hajj, A., Nie, S. \& O’Regan, R. M. (2006). Emerging use of nanoparticles in diagnosis and treatment of breast cancer. The lancet oncology, Vol. 7, pp. 657-667.

Yu, W. W.; Qu, L.; Guo, W. \& Peng, X. (2003). Experimental Determination of the Extinction Coefficient of CdTe, CdSe, and CdS Nanocrystals. Chem. Mater, Vol. 15, pp. 28542860.r 


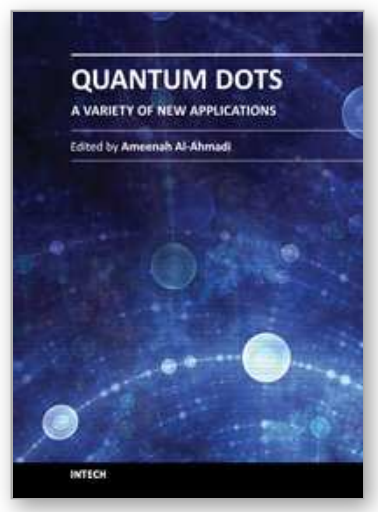

\section{Quantum Dots - A Variety of New Applications}

Edited by Dr. Ameenah Al-Ahmadi

ISBN 978-953-51-0483-4

Hard cover, 280 pages

Publisher InTech

Published online 04, April, 2012

Published in print edition April, 2012

The book "Quantum dots: A variety of a new applications" provides some collections of practical applications of quantum dots. This book is divided into four sections. In section 1 a review of the thermo-optical characterization of CdSe/ZnS core-shell nanocrystal solutions was performed. The Thermal Lens (TL) technique was used, and the thermal self-phase Modulation (TSPM) technique was adopted as the simplest alternative method. Section 2 includes five chapters where novel optical and lasing application are discussed. In section 3 four examples of quantum dot system for different applications in electronics are given. Section 4 provides three examples of using quantum dot system for biological applications. This is a collaborative book sharing and providing fundamental research such as the one conducted in Physics, Chemistry, Biology, Material Science, Medicine with a base text that could serve as a reference in research by presenting up-todate research work on the field of quantum dot systems.

\section{How to reference}

In order to correctly reference this scholarly work, feel free to copy and paste the following:

Adriana Fontes, Beate. S. Santos, Claudilene R. Chaves and Regina C. B. Q. Figueiredo (2012). II-VI Quantum Dots as Fluorescent Probes for Studying Trypanosomatides, Quantum Dots - A Variety of New Applications, Dr. Ameenah Al-Ahmadi (Ed.), ISBN: 978-953-51-0483-4, InTech, Available from: http://www.intechopen.com/books/quantum-dots-a-variety-of-new-applications/ii-vi-quantum-dots-asfluorescent-probes-for-studying-trypanosomatides

\section{INTECH}

open science | open minds

\section{InTech Europe}

University Campus STeP Ri

Slavka Krautzeka 83/A

51000 Rijeka, Croatia

Phone: +385 (51) 770447

Fax: +385 (51) 686166

www.intechopen.com

\section{InTech China}

Unit 405, Office Block, Hotel Equatorial Shanghai

No.65, Yan An Road (West), Shanghai, 200040, China

中国上海市延安西路65号上海国际贵都大饭店办公楼 405 单元

Phone: +86-21-62489820

Fax: $+86-21-62489821$ 
(C) 2012 The Author(s). Licensee IntechOpen. This is an open access article distributed under the terms of the Creative Commons Attribution 3.0 License, which permits unrestricted use, distribution, and reproduction in any medium, provided the original work is properly cited. 